\title{
Differential regulation of mouse and human Mu opioid receptor gene depends on the single stranded DNA structure of its promoter and $\alpha$-complex protein 1
}

\author{
DONG-SUN LEE ${ }^{1,2}$, PING-YEE LAW ${ }^{3}$, WEI LN ${ }^{3}$, HORACE H. LOH ${ }^{3}$, KYU YOUNG SONG ${ }^{3}$ and HACK SUN CHOI ${ }^{1,2}$ \\ ${ }^{1}$ Department of Biotechnology, College of Applied Life Science, Jeju National University; \\ ${ }^{2}$ Subtropical/Tropical Organism Gene Bank Institute, Jeju National University, Jeju 63243, Republic of Korea; \\ ${ }^{3}$ Department of Pharmacology, University of Minnesota Medical School, Minneapolis, MN 55455, USA
}

Received February 22, 2017; Accepted March 7, 2017

DOI: $10.3892 /$ br.2017.877

\begin{abstract}
The Mu opioid receptor (MOR) mediates various functions of opioid-induced analgesia, euphoria and respiratory depression, and is a major target of opioid analgesics. Understanding of MOR gene expression among species is important for understanding its analgesic function in humans. In the current study, the polypyrimidine/polypurine (PPy/u) region, a key element of MOR gene expression, was compared in humans and mice. The mouse PPy/u element is highly homologous to its human element (84\%), and the mouse MOR (mMOR) reporter drives luciferase activity 35-fold more effectively than the human MOR (hMOR) reporter. The structural study of reporter plasmids using $\mathrm{S} 1$ nuclease indicates that the mouse PPy/u element has a particular conformational structure, namely a single-stranded DNA (ssDNA) region that promotes strong promoter activity. DNA electrophoretic mobility shift assays demonstrated that the recombinant $\alpha$-complex protein 1 $(\alpha-\mathrm{CP} 1)$ is capable of binding to a single-stranded mouse PPy/u sequence. Furthermore, plasmid-expressing $\alpha$-CP1 activated the expression of a luciferase reporter when cotransfected with a single-stranded (p336/306) construct. In addition, the $\alpha$-CP1 gene induced the mMOR gene in mouse neuronal cells and did not induce the human neuronal MOR gene. The current study demonstrates that $\alpha-\mathrm{CP} 1$ functions as a transcriptional activator in the mMOR gene, but does not function in the hMOR
\end{abstract}

Correspondence to: Dr Hack Sun Choi, Department of Biotechnology, College of Applied Life Science, Jeju National University, Jeju 63243, Republic of Korea

E-mail: choix074@jejunu.ac.kr

Dr Kyu Young Song, Department of Pharmacology, University of Minnesota Medical School, Minneapolis, MN 55455, USA

E-mail: songx047@umn.edu

Key words: $\alpha$-complex protein 1, polypyrimidine/polypurine region, $\mathrm{Mu}$ opioid receptor, electrophoretic mobility shift assays, poly $(\mathrm{C})$ sequence, transcriptional activator gene due to species-specific structural differences. The differences in human and mouse MOR gene expression are based on $\alpha-C P 1$ and the ssDNA structure of the MOR promoter. The MOR gene is species-specifically regulated, as the PPy/u element adopts a unique species-specific conformation and $\alpha-\mathrm{CP} 1$ recruitment.

\section{Introduction}

Opioids are wildly administered for treatment and control of moderate and severe pains. Their efficiency is dependent on the ability to mimic endogenous peptides on the opioid receptors. Opioid receptors are classified into three types of receptor ( $\mu, \delta$ and $\kappa$ ) characterized by molecular cloning and these receptors have been investigated in numerous pharmacological studies $(1,2)$. The Mu opioid receptor (MOR) is involved in morphine-induced analgesia, tolerance and dependence according to pharmacological studies and analysis of MOR knockout mice (3-5). Upon opioid binding, MOR couples with G-protein-coupled receptors, regulates adenylyl cyclase, intracellular calcium and mitogen-activated protein kinase, then triggers a cascade of intracellular events (6). MOR is a major molecular target of analgesic drugs, morphine, heroin, methadone and fentanyl (7).

MOR is predominantly expressed in the central nervous system, and differential expression of MOR is dependent on receptors of varying densities in different regions $(8,9)$. Individual human and mouse strains differ in their responses to pain and opiate drugs $(10,11)$. Although humans and mice exhibit a different response to opiates, to the best of our knowledge, there have been no studies on these differential responses. Only one study indicated that single nucleotide polymorphisms (SNPs) are associated with mice with differences in morphine preference (12).

Mouse MOR (mMOR) gene expression is regulated by distal and proximal promoters (DP and PP, respectively). The two promoters are similar to housekeeping genes that are lacking a TATA box. The distal promoter is less active, by 20 -fold, than the PP in adult and embryonic mouse brains as determined using reverse transcription-polymerase chain reaction (RT-PCR) (13). The proximal core promoter of the 
mMOR gene contains the polypyrimidine/polypurine (PPy/u) region, and the PP of the human MOR (hMOR) gene contains a similar PPy/u region that is located nearby at transcription initiation site $(14,15)$. The PPy/u region of the mMOR gene promoter strongly activates the MOR gene and contains a 26-bp CT-rich region with overlapping single- and double-stranded DNA sequences, and multiple binding sites for Sp1, Sp3 and single-stranded binding proteins $(16,17)$. Regulation of hMOR gene expression in neuronal cells is not well understood compared with mMOR gene regulation. The hMOR promoter contains a deferoxamine-response CT-rich region that is located close to the translational initiation site (18). PPy/u motifs are the common sequence in eukaryotic cells (19) and possess special chemical properties, including a non-B DNA conformation sensitive to S1 nuclease, a triple-stranded forming DNA structure and guanine-rich guanosine, and a G-quartet structure that is often observed at the centromere and telomere (19).

In the current study, the structural conformation of the $\mathrm{PPy} / \mathrm{u}$ motif and poly $(\mathrm{C})$ binding protein (PCBP1), $\alpha$-complex protein $1(\alpha-\mathrm{CP} 1)$ were demonstrated to regulate different transcriptional activation via the PPy/u motifs on human and mouse MOR genes. To the best of our knowledge, this is the first comparative investigation of the mouse and human MOR gene expression that focuses on the key transcriptional regulatory element sequence $\mathrm{PPy} / \mathrm{u}$ motif and the $\alpha-\mathrm{CP} 1$ protein. Furthermore, the reasons for and theoretical backgrounds regarding why humans and mice exhibit different responses to pain and opiate drugs are explained.

\section{Materials and methods}

Plasmid construction. The mouse promoter construct p336/306 was generated by ligating an annealed double-stranded oligonucleotide into the SacI and HindIII sites of a pGL3-basic vector (Promega Corporation, Madison, WI, USA) using the following oligonucleotide sequences: Sense, 5'-ATTGAGCTC TCCACTCCTTCTCTCTCCTCCCTCCСCTCTAAAGCT TTTC-3') containing a SacI and HindIII site (underlined) and antisense, 5'-GAA AAGCTTTA GAGGGGAGGGAGG AGAGAGAAGGAGTGGAGAGCTC AAT-3' containing a HindIII and SacI site (underlined). The human promoter construct p322/292 was generated by ligating an annealed double-stranded oligonucleotide into the SacI and HindIII sites of pGL3-basic vector using the following oligonucleotide sequences: Sense, 5'-ATTGAGCTCTCCACCCCTTTTCCC TCCTCCCTCCCTTCCAAAGCTTTTC-3' containing a SacI and HindIII site (underlined) and antisense, GAAAAGCTT TGGAAGGGAGGGAGGAGGGAAAAGG GGTGGAGA GCTCAAT-3' containing a HindIII and SacI site (underlined). To clone the $\alpha-\mathrm{CP} 1$ gene, total RNA was isolated from mouse NS20Y cells obtained from the American Type Culture Collection (ATCC; Manassas, VA, USA). RNA was treated with RNase-free DNase (Promega Corporation) according to the manufacturer's instructions. RT-PCR was performed using the OneStep RT-PCR kit (Qiagen, Inc., Valencia, CA, USA). PCR was performed with primers that were designed using the gene sequence information for each protein: $\alpha$-CP1 (Gene ID, 13435897): Sense primer, 5'-CCATGGACGCCGGTG TGACTGA-3' and antisense primer, 5'-GCTGCACCCCAT
CCCCTTCTC-3'. The PCR conditions were as follows: $94^{\circ} \mathrm{C}$ for $3 \mathrm{~min}$; 35 cycles of $94^{\circ} \mathrm{C}$ for $1 \mathrm{~min}, 55^{\circ} \mathrm{C}$ for $1 \mathrm{~min}$, and $72^{\circ} \mathrm{C}$ for $1 \mathrm{~min}$; and $72^{\circ} \mathrm{C}$ for $10 \mathrm{~min}$. RT-PCR products were excised from a $1 \%$ agarose gel, purified using a QIAQuick gel extraction kit (Qiagen, Inc.) and cloned into a pCRII-TOPO vector (Invitrogen; Thermo Fisher Scientific, Inc., Waltham, MA, USA). The candidate plasmids containing inserts of the correct size were confirmed using restriction enzyme digestion and DNA sequencing on an ABI 3100 sequencer (Applied Biosystems; Thermo Fisher Scientific, Inc.). For the transient expression studies, the $\alpha$-CP1 gene was cloned by digesting the above-mentioned pCRII-TOPO $\alpha$-CP1 clone with 5'-HindIII and 3'-XhoI into the same sites of a pcDNA4 vector (Invitrogen; Thermo Fisher Scientific, Inc.), generating a pcDNA4- $\alpha-\mathrm{CP} 1$ plasmid. DNA sequences of all constructs were confirmed using DNA sequencing. For the protein expression studies in Escherichia coli, the $\alpha$-CP1 gene was cloned by digesting the above-mentioned pcDNA4- $\alpha$-CP1 plasmid with 5'-HindIII and $3^{\prime}-\mathrm{XhoI}$ into the same sites of a pET21b vector (EMD Millipore, Billerica, MA, USA), generating a pET21b- $\alpha$-CP1 plasmid. The DNA sequences of all constructs were confirmed using DNA sequencing.

$\alpha-C P 1$ protein expression. The $\alpha-\mathrm{CP} 1$ protein expression was performed as described previously (20). The protein was expressed in a Lysogeny broth medium (Sigma-Aldrich; Merck KGaA, Darmstadt, Germany) containing ampicillin $(50 \mu \mathrm{g} / \mathrm{ml})$. To obtain the protein, several cell growth conditions were generated by varying the temperature $(16,30$ and $37^{\circ} \mathrm{C}$ ) and isopropyl $\beta$-D-1-thiogalactopyranoside (IPTG) concentration (0.1, 0.5 and $1 \mathrm{mM}$ ). Typically, $2 \mathrm{ml}$ overnight culture was added to $100 \mathrm{ml}$ medium and incubated with vigorous shaking at $\sim 37^{\circ} \mathrm{C}$. When the culture reached optical density $(\mathrm{OD})_{600}=0.5$, protein expression was induced with $1 \mathrm{mM}$ IPTG. Subsequent to induction, the samples were further incubated at $37^{\circ} \mathrm{C}$ for $4 \mathrm{~h}$. The cells were harvested by centrifugation at $10,000 \times \mathrm{g}$ for $10 \mathrm{~min}$ at $4^{\circ} \mathrm{C}$, washed with TE buffer (10 mM Tris- $\mathrm{HCl}$ and $1 \mathrm{mM}$ EDTA; $\mathrm{pH} 8.0)$ and stored at $-80^{\circ} \mathrm{C}$.

Folding of the $\alpha$-CP1 protein. The folding of the $\alpha$-CP1 protein was performed as described previously (20). The twice water-washed inclusion bodies were resuspended in 5 volumes of Buffer C (20 mM Tris-HCl, $1 \mathrm{mM}$ EDTA, $10 \mathrm{mM}$ DTT and $8 \mathrm{M}$ Urea; $\mathrm{pH}$ 7.0), stirred at room temperature for $60 \mathrm{~min}$ and centrifuged at $10,000 \mathrm{x} g$ for $15 \mathrm{~min}$ at room temperature. The pellet was discarded and the supernatant $(5-10 \mathrm{mg} / \mathrm{ml})$ was collected in a fresh tube. The refolding experiments were performed using protein-folding spin-columns following the manufacturer's recommendation (ProFoldin, Hudson, MA, USA).

Preparation of inclusion bodies and purification of recombinant $\alpha-C P 1$ protein. The preparation of inclusion bodies and purification of recombinant of the $\alpha-\mathrm{CP} 1$ protein were performed as described previously (20). The cell pellet was resuspended in $30 \mathrm{ml}$ Buffer A $(20 \mathrm{mM}$ Tris- $\mathrm{HCl}, 100 \mathrm{mM}$ $\mathrm{NaCl}$ and $1 \mathrm{mM}$ PMSF; $\mathrm{pH} 7.0$ ) and sonicated at $4^{\circ} \mathrm{C}$ with 5 cycles. The lysate was centrifuged at $10,000 \times \mathrm{x}$ for $15 \mathrm{~min}$ at $4^{\circ} \mathrm{C}$. The pellet was resuspended in 5 volumes of Buffer $\mathrm{A}$, 
A
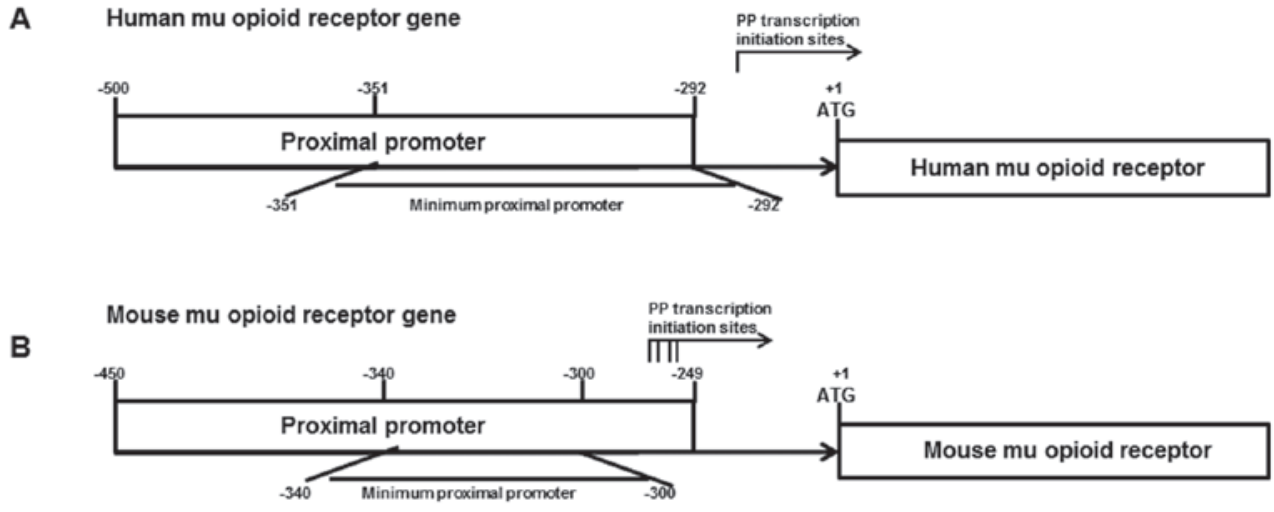

C

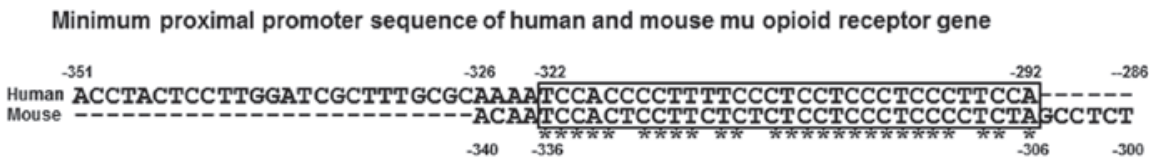

Figure 1. PP of the (A) human and (B) mouse MOR genes. Schematic representation of the PPs of the human and mouse MOR genes. The nucleotide +1 corresponds to the translation start site (ATG). (C) PPy/u sequences and homology of the MOR PP in humans and mice. MOR, mu opioid receptor; PP, proximal promoter; PPy/u, polypyrimidine/polypurine.

stirred at room temperature for $5 \mathrm{~min}$ and centrifuged at $10,000 \mathrm{x} g$ for $15 \mathrm{~min}$ at $4^{\circ} \mathrm{C}$. The inclusion bodies were then washed three times with 10 volumes of $20 \mathrm{mM}$ Tris- $\mathrm{HCl}$ containing $100 \mathrm{mM} \mathrm{NaCl}$ at $\mathrm{pH} \mathrm{7.0.} \mathrm{The} \mathrm{inclusion} \mathrm{body}$ pellet was resuspended in $30 \mathrm{ml}$ Buffer $\mathrm{B}$ [50 mM NaH $\mathrm{mO}_{4}$, $300 \mathrm{mM} \mathrm{NaCl}$ ( $\mathrm{pH} 8.0$ ) and $8 \mathrm{M}$ urea] to solubilize the inclusion bodies. Sonication was necessary to suspend the pellet. The suspension was centrifuged at $10,000 \times \mathrm{g}$ for $20 \mathrm{~min}$ and the supernatant was transferred to fresh clean tubes. The supernatant was then added to an equilibrated Ni-NTA column (Qiagen, Inc.) and allowed to drain. The column was washed with Buffer B, and the $6 \mathrm{x}$ His-tagged $\alpha-\mathrm{CP} 1$ was eluted using an elution buffer $\left[50 \mathrm{mM} \mathrm{NaH} \mathrm{PO}_{4}, 300 \mathrm{mM}\right.$ $\mathrm{NaCl}, 250 \mathrm{mM}$ imidazole ( $\mathrm{pH}$ 8.0) and $8 \mathrm{M}$ urea]. Anti-His antibodies were purchased from Sigma-Aldrich; Merck $\mathrm{KGaA}$. To determine which fractions contain the His-tagged $\alpha-\mathrm{CP} 1$, an aliquot of each sample was analyzed using $10 \%$ SDS-PAGE.

SDS-PAGE, in-gel tryptic digestion and matrix-assisted laser desorption ionization-time of flight (MALDI-TOF) mass spectrometric analysis of $\alpha-C P 1$. The purified $\alpha-C P 1$ protein was resolved on a $10 \%$ SDS-PAGE gel. The Coomassie blue-stained gel was destained, and a gel slice containing the band of interest was subjected to in-gel tryptic digestion as described previously $(20,21)$. The tryptic peptides were extracted with $5 \%$ acetic acid, followed by $5 \%$ acetic acid and $50 \%$ acetonitrile. The samples were dissolved in 5\% acetic acid and desalted using ZipTip ${ }^{\mathrm{TM}} \mathrm{C} 18$ reverse-phase desalting Eppendorf tips (EMD Millipore). The peptides were eluted with $2 \%$ acetonitrile containing $0.1 \%$ TFA in a volume of $20 \mu 1$. The samples were analyzed using a MALDI-TOF mass spectrometer (Applied Biosystems; Thermo Fisher Scientific, Inc.). The masses of the monoisotopic peaks were compared with a theoretical digestion of the protein by trypsin. Mascot database searching software (Matrix Science; http://www. matrixscience.com) was used to identify the $\alpha-\mathrm{CP} 1$ protein.

DNA electrophoretic mobility shift assay (EMSA). The EMSA was performed as described previously $(20,22)$. The polypyrimidine/polypurine (PPy/u) oligonucleotide, single-stranded probe (5'-TCCACTCCTTCTCTCTCСТCССТССССТCT A-3') was end-labeled with $\left[\gamma^{3}{ }^{32} \mathrm{P}\right]$ dATP. The free nucleotides were separated using centrifugation at $1,100 \times \mathrm{g}$ for $4 \mathrm{~min}$ at room temperature through a Sephadex G-25 column (Roche Diagnostcs, Indianapolis, IN, USA). The end-labeled ssDNA probes were incubated with recombinant $\alpha$-CP1 $(0.5 \mu \mathrm{g})$ in a final volume of $20 \mu \mathrm{l}$ EMSA buffer [10 mM Tris ( $\mathrm{pH} 7.5), 5 \%$ glycerol, $1 \mathrm{mM}$ EDTA, $50 \mathrm{mM} \mathrm{NaCl}, 1 \mathrm{mM}$ DTT, $0.1 \mathrm{mg} / \mathrm{ml}$ poly $(\mathrm{dI}-\mathrm{dC})]$ at room temperature for $20 \mathrm{~min}$. For the oligonucleotide competition analyses, a 100-fold molar excess of a cold competitor oligonucleotide was added to the mixture prior to adding the probe. The reactions were then incubated at $4^{\circ} \mathrm{C}$ for $30 \mathrm{~min}$. The reaction mixtures were electrophoresed at $160 \mathrm{~V}$ for $2 \mathrm{~h}$ on a non-denaturing $4 \%$ polyacrylamide gel in $0.5 \mathrm{X}$ TBE (45 mM Tris-borate and $1 \mathrm{mM}$ EDTA) at $4^{\circ} \mathrm{C}$ and visualized using autoradiography.

S1 nuclease sensitivity assay. The pGL-basic plasmids, p322/292 and p336/306, were digested with various quantities of the $\mathrm{S} 1$ nuclease (Promega Corporation) in $\mathrm{S} 1$ nuclease buffer for $15 \mathrm{~min}$ at $37^{\circ} \mathrm{C}$ as described previously (20). The digestion was terminated using phenol/chloroform extraction and the plasmids were recovered by precipitation. The resulting S1-treated plasmids were digested further using $\mathrm{XbaI}$ (Promega Corporation) and the products were resolved using electrophoresis on a $1 \%$ agarose gel at $100 \mathrm{~V}$ for $1 \mathrm{~h}$.

Transient transfection and reporter gene assays. Mouse neuroblastoma NS20Y cells and human neuronal NMB cells 
A

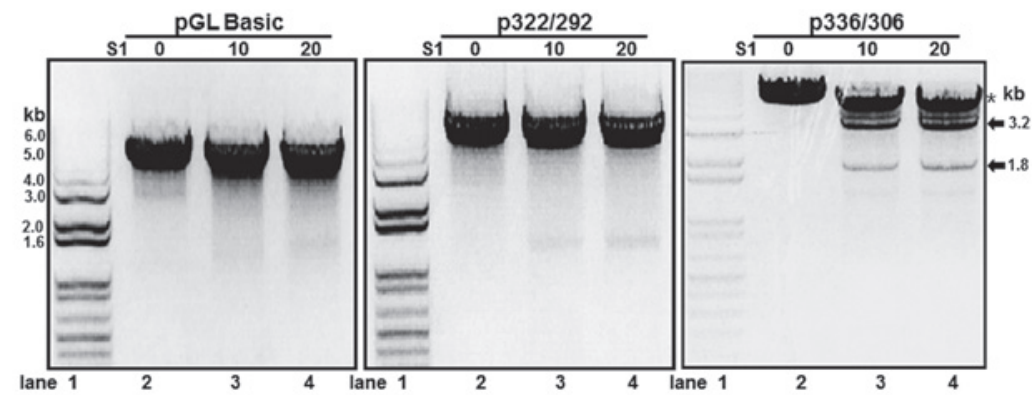

B
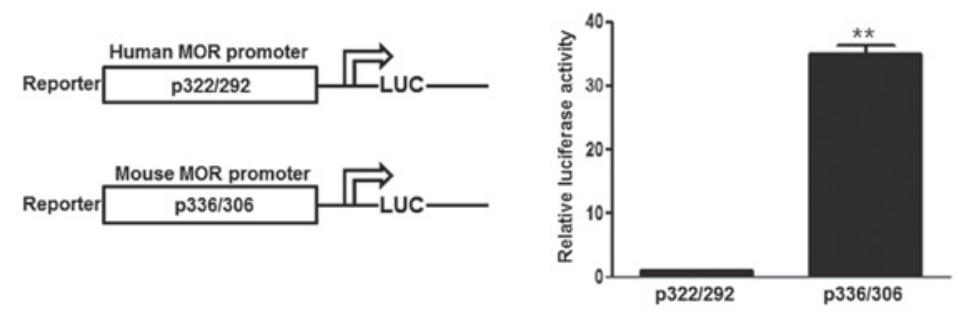

Figure 2. S1 nuclease sensitivity of PPy/u motif-containing plasmids. (A) The PPy/u motif-containing promoters fused with the promoterless pGL3-basic vector (p322/292 and p336/306) and pGL3-basic (control) were treated with vehicle (lane 2 in each panel) and increasing quantities of S1 nuclease (lanes 3 and 4 in each panel) followed by digestion with the $X b a \mathrm{I}$ restriction enzyme. Lane 1, molecular size markers (1-kb ladder). The XbaI-linearized plasmid (denoted by the single asterisk) and the 3.2- and 1.8-kb fragments are indicated by arrows. (B) The luciferase activity of p322/292 and p336/306 plasmids. Activities of luciferase reporter were expressed as $n$-fold relative to the activity of each corresponding luciferase reporter transfected with vector p322/292, which was assigned an activity value of 1.0. Transfection efficiencies were normalized to $\beta$-galactosidase activity. Data are presented as the mean of three independent experiments with at least two different plasmid preparations. Standard deviation is indicated by the error bars. ${ }^{* *} \mathrm{P}<0.05$ vs. control. PPy/u, polypyrimidine/polypurine.

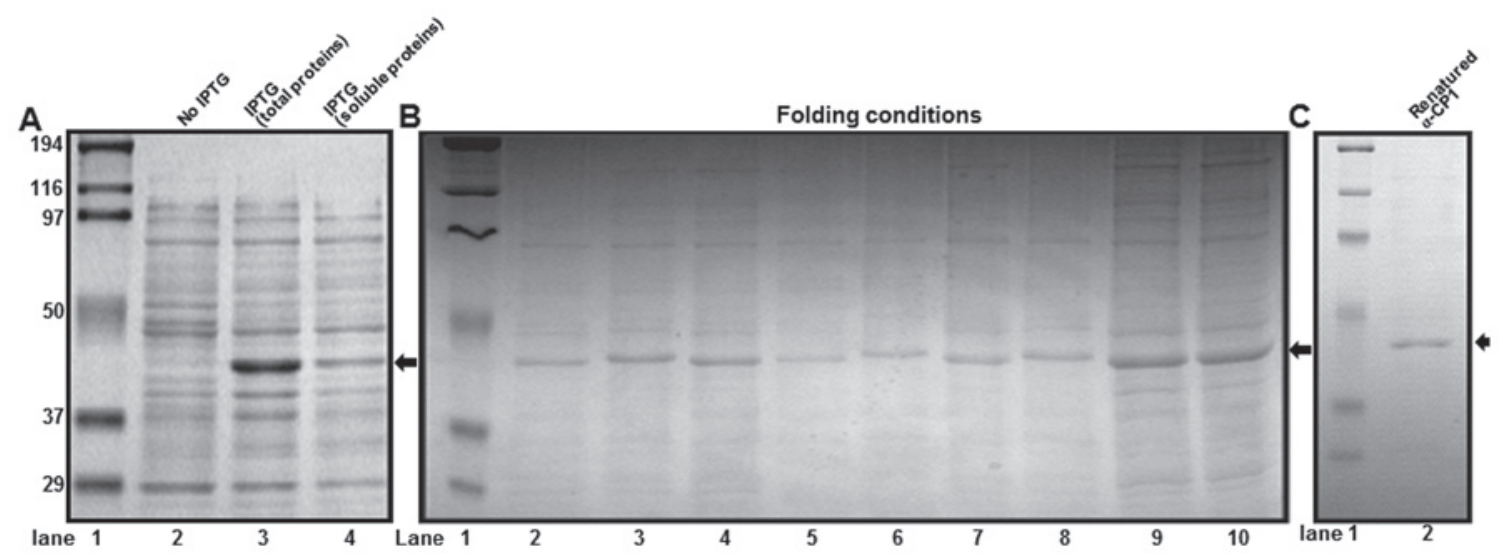

Figure 3. Expression, purification and folding conditions of recombinant $\alpha$-CP1 protein. (A) 10\% SDS-PAGE analysis of recombinant mouse $\alpha$-CP1 protein expressed by an Escherichia coli (E. coli)-induced expression system (1 mM IPTG at $\left.37^{\circ} \mathrm{C}\right)$. Lane 1, protein molecular weight markers; lane $2,10 \mu 1$ total protein from E. coli BL21 (DE3)/pET21b- $\alpha$-CP1 before induction; lane 3, $10 \mu 1$ total protein from E. coli BL21 (DE3)/pET21b- $\alpha$-CP1 after induction; lane 4, $10 \mu \mathrm{l}$ soluble protein from E. coli BL21 (DE3)/pET21b- $\alpha$-CP1 after induction. (B) The optimization of folding conditions for the purified recombinant mouse $\alpha$-CP1. The solubilized inclusion bodies $(5-10 \mathrm{mg} / \mathrm{ml})$ were processed using a protein-folding spin-column screening kit. Lane 1, protein molecular weight markers; lanes 2-10, eluates from spin-columns nos. 1-9. (C) 10\% SDS-PAGE analysis of the affinity-purified renatured recombinant mouse $\alpha$-CP1. Lane 1, protein molecular weight markers; lane 2, $5 \mu 1$ refolded and purified $\alpha$-CP1 protein. $\alpha$-CP1, $\alpha$-complex protein 1; IPTG, isopropyl $\beta$-D-1-thiogalactopyranoside .

obtained from the ATCC were grown in Dulbecco's modified Eagle's medium supplemented with $10 \%$ heat-inactivated fetal bovine serum (GE Healthcare Life Sciences, Chalfont, UK) at $37^{\circ} \mathrm{C}$ in a humidified atmosphere of $5 \% \mathrm{CO}_{2} . \mathrm{NS} 20 \mathrm{Y}$ cells were plated in 6-well dishes at a concentration of $0.5 \times 10^{6}$ cells/well and cultured overnight before transfection. Equimolar concentrations of various plasmids were transfected using the Effectene transfection reagent (Qiagen, Inc.) as described previously $(20,23)$. Briefly, for the luciferase analysis of the $\mathrm{p} 336 / 306$ and $\mathrm{p} 322 / 292$ promoters, $0.5 \mu \mathrm{g}$ of the reporter plasmids was combined with the Effectene transfection reagent for
10 min before being added to the NS20Y cells. Forty-eight $h$ after transfection, the cells that were grown to confluence were washed once with phosphate-buffered saline and lysed with lysis buffer (Promega Corporation). To correct for differences in transfection efficiency, a one-fifth molar ratio of pCH110 (GE Healthcare Life Sciences) containing the $\beta$-galactosidase gene under the SV40 promoter was included in each transfection for normalization. The luciferase (Promega Corporation) and $\beta$-galactosidase (Promega Corporation) activities of each lysate were determined according to the manufacturer's recommendations. 
RT-PCR and heterologous expression of $\alpha-C P 1$. Total RNA was isolated using TRI Reagent (Molecular Research Center, Inc., Cincinnati, OH, USA) according to the supplier's protocol. For RT-PCR, $2 \mu \mathrm{g}$ total RNA and the OneStep RT-PCR reagent (Qiagen, Inc.) were used. The PCR cycle conditions consisted of $95^{\circ} \mathrm{C}$ for $1 \mathrm{~min}, 60^{\circ} \mathrm{C}$ for $1 \mathrm{~min}$ and $72^{\circ} \mathrm{C}$ for $1 \mathrm{~min}$ followed by a 10 -min extension at $72^{\circ} \mathrm{C}$. Mouse-specific primers were as follows: 5'-CATCAAAGCACTGATCACGATTCC-3' and 5'-TAGGGCAATGGAGCAGTTTCTGC-3' for MOR; 5'-TGG CCTTAGGGTGCAGGGGG-3' and 5'-GTGGGCCGCTCT AGGCACCA-3' for $\beta$-actin. The human-specific primers were as follows: 5'-CCTTCCTGGGCATGGAGTCCTG-3' and 5'-TACAGCGAGGCCAGGATGG-3' for $\beta$-actin; 5 '-CTG GAAGGGCAGGGTACTGGTG-3' and 5'-CTGCCCCCA CGAACGCCAGCAAT-3' for MOR.

Statistical analysis. All data were presented as the mean \pm standard deviation. Data were analyzed using Student's t-test. $\mathrm{P}<0.05$ was considered to indicate a statistically significant difference and GraphPad Prism 5 Software (GraphPad Software, Inc., La Jolla, CA, USA) was used to perform the analyses.

\section{Results}

Promoter structure and comparison of the minimum PP sequence of human and mouse MOR gene. Transcription of the mMOR gene starts at four sites located between -291 and -268 of the MOR gene using two promoters: The PP (-450 to -249) and the DP $(-1,326$ to +1 ; Fig. 1B). The PP was responsible for major MOR gene activity ( $95 \%)$ in the mouse brain. The regulatory elements of the PP contained PPy/u and a canonical Sp1 binding site. The PPyy/u exhibited an ssDNA conformational structure (15). Transcription of the hMOR gene starts at the -256 site and the hMOR gene also uses two promoters: The PP (-500 to -292$)$ and the DP (-2,388 to +1; Fig. 1A). The regulatory elements of the human PP contained PPy/u and a canonical $\mathrm{Sp} 1 / 3$ binding site. Structural analysis of MOR $\mathrm{PPy} / \mathrm{u}$ indicated that mMOR PPy/u is highly homologous to hMOR PPy/u (84\%; Fig. 1C).

Differential S1 nuclease sensitivity and promoter activity of human and mouse MOR promoters containing PPy/u motifs. ssDNA structures derived from the non-B DNA form or intracellular triple helix structures are sensitive to low concentrations of S1 nuclease (15). In order to analyze the structural differences of human and mouse MOR PPy/u motifs, an S1 nuclease treatment was performed in the current study. A p322/292 plasmid containing the human PPy/u motif was treated with $\mathrm{S} 1$ nuclease and digested with $X b a \mathrm{I}$. In the presence of $\mathrm{S} 1$ nuclease, the $X b a \mathrm{I}$ treatment produced a 5-kb linear DNA (Fig. 2A, middle panel). In addition, the pGL-basic plasmid demonstrated a similar result (Fig. 2A, left panel). A p336/306 plasmid containing the mouse PPy/u motif was treated with $\mathrm{S} 1$ nuclease and digested with $\mathrm{Xba \textrm {I }}$. Two DNA bands, 3.2 and $1.8 \mathrm{~kb}$, were produced and the band density was increased with increasing quantities of S1 nuclease (Fig. 2A, right panel). These results indicate that the mouse $\mathrm{PPy} / \mathrm{u}$ motif is an ssDNA structure, whereas the human motif is a double-stranded DNA, as determined according to the S1 nuclease assay. To confirm the association between structure

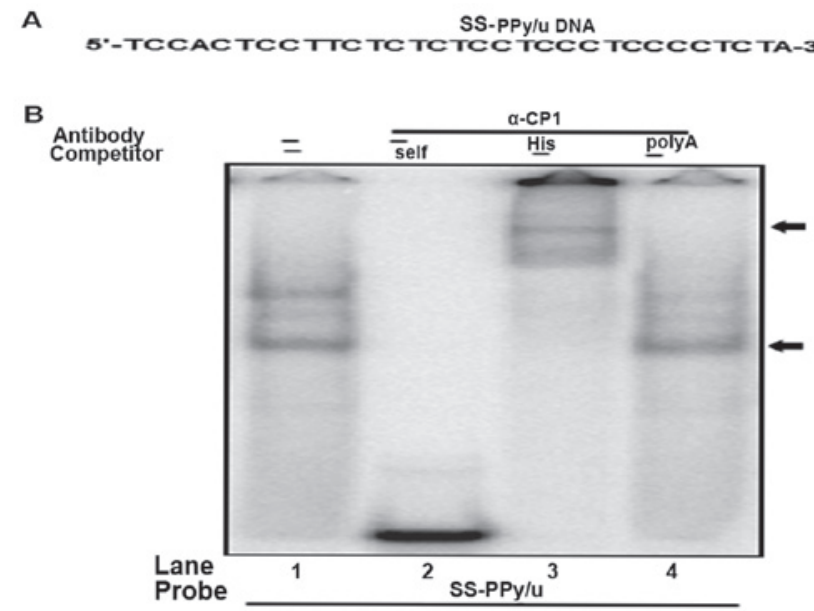

Figure 4. DNA EMSA of recombinant $\alpha$-CP1 protein. (A) The DNA EMSA of recombinant mouse His-tagged $\alpha$-CP1 using an ssDNA probe. EMSA was performed on purified recombinant $\alpha$-CP1 using a ${ }^{32} \mathrm{P}-$ labeled ssDNA sequence as a probe. Lane 1 , purified $\alpha$-CP1 without antibody; lane 2, self-competition; lane 3, purified $\alpha$-CP1 protein with an anti-His antibody; lane 4 , purified $\alpha-\mathrm{CP} 1$ protein with a poly (A) competitor. The $\alpha$-CP1/poly $(\mathrm{C})$ and $\alpha-\mathrm{CP} 1 / \operatorname{poly}(\mathrm{C}) / \mathrm{His}$-antibody complexes are indicated by arrows. EMSA, electrophoretic mobility shift assay; $\alpha$-CP1, $\alpha$-complex protein 1; ss, single-stranded; PPy/u, polypyrimidine/polypurine.

and gene expression, a reporter assay was used. The mouse construct in the p336/306 plasmid exhibited strong promoter activity when compared with the human construct p322/292 promoter activity in mouse NS20Y cells (Fig. 2B).

Expression, folding and purification of $\alpha-C P 1 . \alpha-\mathrm{CP} 1$ is a poly $(\mathrm{C})$ binding protein, which is an ssDNA binding protein. The mouse $\alpha-\mathrm{CP} 1$ gene was cloned into the pET21b vector and the recombinant $\alpha-\mathrm{CP} 1$ protein contained a $\mathrm{C}$-terminal 6X His tag. To obtain the optimal condition for expressing the soluble $\alpha-\mathrm{CP} 1$ protein in $E$. coli BL21 (DE3), various conditions, including temperature for cell growth, cell culture media and induction times were evaluated. However, all conditions produced insoluble $\alpha$-CP1. To obtain the maximum production of insoluble $\alpha-\mathrm{CP} 1$, the expression conditions were optimized using a variety of options including temperatures and IPTG concentrations. Under optimal conditions, production of insoluble $\alpha$-CP1 was $\sim 30 \%$ (Fig. 3A). To optimize the $\alpha-\mathrm{CP} 1$ protein folding conditions, a spin-column protein folding screening kit was used, which included nine different protein-folding columns that represent the nine most promising folding conditions. The \#8 column from the kit was selected as the optimal folding condition of the denatured $\alpha-\mathrm{CP} 1$ protein (Fig. 3B). Using Ni-NTA His-binding resin, denatured $\alpha$-CP1 protein was purified with $8 \mathrm{M}$ urea. The purified $\alpha-\mathrm{CP} 1$ protein was subsequently folded using the spin-column protein folding screening kit \#8 column. The purified and folded $\alpha$-CP1 protein was confirmed using 10\% SDS-PAGE and Coomassie staining (Fig. 3C).

DNA binding property of $\alpha$-CP1. To determine the physical interaction of purified $\alpha-\mathrm{CP} 1$ protein and single-stranded PPy/u, DNA EMSA was performed using purified $\alpha$-CP1 protein and ${ }^{32} \mathrm{P}$-labeled single-stranded $\mathrm{PPy} / \mathrm{u}$ oligonucleotide (Fig. 4A). The specificity of $\alpha$-CP1 protein/single-stranded 
A

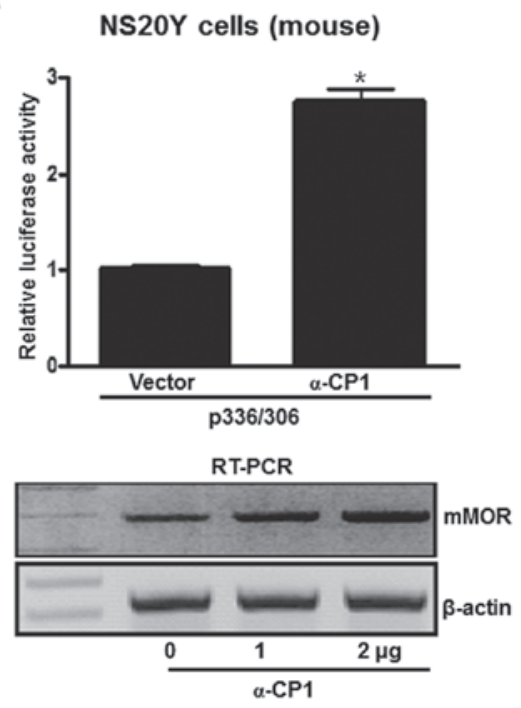

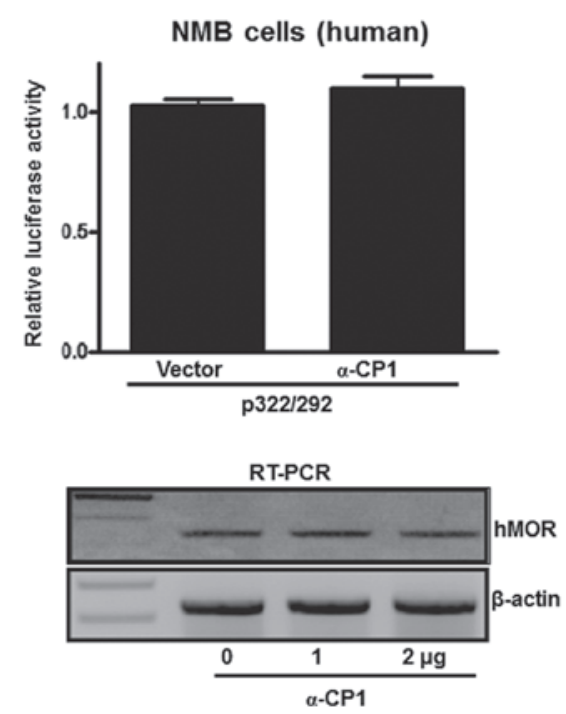

Figure 5. Effect of $\alpha$-CP1 on the mouse and human MOR gene in neuronal cells. (A) $\alpha$-CP1 activates the PPy/u sequence-containing promoter (p336/306) and MOR mRNA expression levels in $\alpha$-CP1 cDNA-transfected mouse neuronal NS20Y cells. (B) $\alpha$-CP1 does not activate the PPy/u sequence-containing promoter (p322/292) and hMOR mRNA expression levels in $\alpha$-CP1 cDNA-transfected human neuronal NMB cells. The luciferase activity is expressed as $\mathrm{n}$-fold relative to the activity of the luciferase reporter transfected with vector alone (assigned an activity value of 1.0). The transfection efficiencies were normalized against $\beta$-galactosidase activity. These data are representative of three independent experiments with at least two different plasmid preparations. The bars indicate the range of the standard deviation. " $\mathrm{P}<0.05$ vs. control. Total RNAs from NS20Y cells and NMB cells transfected with varying quantities of pcDNA4- $\alpha$-CP1 plasmid were reverse-transcribed into cDNA, which was used as a template for PCR using MOR gene-specific PCR primers and $\beta$-actin primers as indicated. PCR products were electrophoresed on a $2 \%$ agarose gel and the relative densities of MOR mRNA were normalized to $\beta$-actin. Only the DNA vector was transfected, and 1 and $2 \mu \mathrm{g}$ of each pcDNA4- $\alpha$-CP1 plasmid DNA was transfected. The total quantity of DNA transfected was equalized using vector pcDNA4 DNA. The results are of at least three independent transfection experiments performed in triplicate. $\alpha$-CP1, $\alpha$-complex protein 1 ; MOR, Mu opioid receptor; PPy/u, polypyrimidine/polypurine; hMOR, human MOR; mMOR, mouse MOR; RT-PCR, reverse transcription-polymerase chain reaction.

PPy/u was verified using an unlabeled excess self-competitor (Fig. 4B, lane 2) and poly A competitor (Fig. 3D, lane 4). Furthermore, an anti-His antibody for DNA EMSA was used. The formation of the $\alpha-\mathrm{CP} 1$ protein/single-stranded-PPy/u complex was abolished by the addition of a His antibody and a super shift, indicating a specific interaction between $\alpha$-CP1 protein and single-stranded PPy/u (Fig. 4B, lane 3).

Differential promoter activity and endogenous transcription regulation between mouse and human MOR genes via $\alpha$-CP1. To examine differential promoter activity between mouse and human MOR genes via the $\alpha$-CP1 gene, an $\alpha$-CP1 expression plasmid and mouse/human PPy/u sequence-containing luciferase plasmids were co-transfected into mouse neuronal cells (NS20Y). $\alpha$-CP1 activated $280 \%$ of p336/306 activity. Additionally, an $\alpha-\mathrm{CP} 1$ expression plasmid and human PPy/u sequence-containing luciferase plasmid was co-transfected into human neuronal cells (NMB). The $\alpha-\mathrm{CP} 1$ did not activate the p322/292 promoter (Fig. 5A and B). To estimate whether transiently overexpressed $\alpha-\mathrm{CP} 1$ results in the upregulation of endogenous MOR transcripts, RT-PCR analysis using MOR-specific primers was performed with total RNA from the NS20Y and NMB cells transfected with varying quantities $(0-2 \mu \mathrm{g})$ of pcDNA4- $\alpha \mathrm{CP} 1$, as well as with the pcDNA4 vector control. $\alpha$-CP1 upregulated endogenous mMOR gene expression in a dose-dependent manner. However, the hMOR gene was not upregulated by the $\alpha-\mathrm{CP} 1$ gene. These results indicate that $\alpha-C P 1$ acts as a transcriptional activator of the mMOR gene dependent on the ssDNA structure. In addition, the $\alpha-C P 1$ protein is important in the regulation of $\mathrm{mMOR}$ gene expression. The human and mouse MOR genes contain a similar PPy/u sequence, but exhibit differential MOR gene regulation.

\section{Discussion}

Comparing two genomic sequences from mice and humans provides strong resolving power. The conserved sequences of associated species, namely human and mouse, exhibited similar functions and gene regulation. The similar sequences offer the opportunity of using the mouse as an animal model to investigate human disease and biology $(16,24)$. Understanding MOR gene expression is particularly important to establish its analgesic function in humans. Transcriptional regulation of the MOR gene is predominantly investigated in mice, and numerous transcription factors [Sp1, Sp3, PCBP, RE-1 silencing transcription factor and poly (ADP-ribose) polymerase 1] are involved in mMOR gene regulation (25). In the present study, the PPy/u region, a key element of MOR gene expression in humans and mouse was investigated. Species-specific PPy/u motifs differentially confer S1 nuclease hypersensitivity under acidic $\mathrm{pHs}$ and exhibited transcription regulation. For example, the PPy/u motif of cystic fibrosis, the transmembrane conductance regulatory gene, is species specific (26). The mouse PPy/u element of the MOR gene is highly homologous to its human element (84\%) (Fig. 1C) and the mMOR reporter exhibited 35-fold increased luciferase activity when compared with the hMOR reporter (Fig. 2B). The structural analysis of reporter plasmids using $\mathrm{S} 1$ nuclease indicates that the mouse PPy/u element has a special conformational structure, namely 
an ssDNA region (Fig. 2A). The current study demonstrates that the underlying mechanism of MOR gene activation by the PPy/u motif in mice differs from that of humans based on different DNA conformations. A previous study indicated that the mouse PPy/u motif, a single stranded cis-regulatory element, and PCBP1, an $\alpha$-CP1 trans-acting protein, are important for MOR PP activity (15). The present study demonstrated that $\alpha-\mathrm{CP} 1$ enhanced MOR promoter activity and endogenous MOR transcription via $\alpha-\mathrm{CP} 1$ binding to the ssDNA element (17). To the best of our knowledge, this is the first study to solubilize, fold, purify and produce a functionally active $\alpha$-CP1 for DNA EMSA analysis using the $E$. coli protein expression system.

In the current study, differential promoter activity and endogenous transcription regulation of the mouse and human MOR gene by $\alpha$-CP1 were investigated. A similar sequence of the PPy/u motif in the human and mouse MOR promoter exhibited a different pattern of promoter activity and endogenous transcription regulation (Fig. 5). Generally, the promoter of the PPy/u sequence is sensitive to S1 nuclease and its plasmid is regulated by single-stranded binding proteins (for example, heterogeneous ribonucleoprotein K and PCBP1-3). However, the hMOR promoter containing the PPy/u sequence is insensitive to $\mathrm{S} 1$ nuclease and its plasmid was not regulated by single-stranded binding protein $\alpha-\mathrm{CP} 1$. The present study hypothesized that plasmids containing human PPy/u do not have a single-stranded DNA conformation.

In conclusion, the differing function of $\alpha-\mathrm{CP} 1$ in humans and mice is determined by its localization in the cell. The post-transcriptional regulator $\alpha$-CP1 is localized in the cytosol, whereas the transcriptional regulator $\alpha-\mathrm{CP} 1$ is localized in the nucleus. Furthermore, transcriptional regulation of the MOR gene is regulated by $\alpha$-CP1 localization. To the best of our knowledge, the present study is the first to compare the human and mouse MOR genes based on PPy/u motif and $\alpha$-CP1. The results partially can explain why MOR gene expression in humans and mice have different responses to painful stimuli and morphine.

\section{Acknowledgements}

The study was supported by the Basic Science Research Program through National Research Foundation of Korea (NRF) funded by the Ministry of Education (grant nos. NRF-2015R1D1A1A01058724, NRF-2011-0006924 and 2016R1A6A1A03012862).

\section{References}

1. Min BH, Augustin LB, Felsheim RF, Fuchs JA and Loh HH: Genomic structure analysis of promoter sequence of a mouse mu opioid receptor gene. Proc Natl Acad Sci USA 91: 9081-9085, 1994.

2. Wei LN and Loh HH: Regulation of opioid receptor expression. Curr Opin Pharmacol 2: 69-75, 2002.

3. Kieffer BL: Recent advances in molecular recognition and signal transduction of active peptides: Receptors for opioid peptides. Cell Mol Neurobiol 15: 615-635, 1995.

4. Kieffer BL: Opioids: First lessons from knockout mice. Trends Pharmacol Sci 20: 19-26, 1999.

5. Law PY, Loh HH and Wei LN: Insights into the receptor transcription and signaling: Implications in opioid tolerance and dependence. Neuropharmacology 47 (Suppl 1): S300-S311, 2004.
6. Law PY, Wong YH and Loh HH: Molecular mechanisms and regulation of opioid receptor signaling. Annu Rev Pharmacol Toxicol 40: 389-430, 2000.

7. Matthes HW, Maldonado R, Simonin F, Valverde O, Slowe S, Kitchen I, Befort K, Dierich A, Le Meur M, Dollé P, et al: Loss of morphine-induced analgesia, reward effect and withdrawal symptoms in mice lacking the mu-opioid-receptor gene. Nature 383: 819-823, 1996.

8. Mansour A, Fox CA, Akil H and Watson SJ: Opioid-receptor mRNA expression in the rat CNS: Anatomical and functional implications. Trends Neurosci 18: 22-29, 1995.

9. Uhl GR, Sora I and Wang Z: The mu opiate receptor as a candidate gene for pain: Polymorphisms, variations in expression, nociception and opiate responses. Proc Natl Acad Sci USA 96: 7752-7755, 1999.

10. Mogil JS: The genetic mediation of individual differences in sensitivity to pain and its inhibition. Proc Natl Acad Sci USA 96: 7744-7751, 1999.

11. Korostynski M, Kaminska-Chowaniec D, Piechota M and Przewlocki R: Gene expression profiling in the striatum of inbred mouse strains with distinct opioid-related phenotypes. BMC Genomics 7: 146, 2006.

12. Doyle GA, Sheng XR, Schwebel CL, Ferraro TN, Berrettini WH and Buono RJ: Identification and functional significance of polymorphisms in the mu-opioid receptor gene (Oprm) promoter of C57BL/6 and DBA/2 mice. Neurosci Res 55: 244-254, 2006.

13. Ko JL, Chen HC and Loh HH: Differential promoter usage of mouse mu-opioid receptor gene during development. Brain Res Mol Brain Res 104: 184-193, 2002.

14. Ko JL, Liu HC, Minnerath SR and Loh HH: Transcriptional regulation of mouse mu-opioid receptor gene. J Biol Chem 273: 27678-27685, 1998.

15. Ko JL and Loh HH: Single-stranded DNA-binding complex involved in transcriptional regulation of mouse mu-opioid receptor gene. J Biol Chem 276: 788-795, 2001.

16. Choe CY, Dong J, Law PY and Loh HH: Differential gene expression activity among species-specific polypyrimidine/polypurine motifs in mu opioid receptor gene promoters. Gene 471: 27-36, 2011.

17. Choi HS, Song KY, Hwang CK, Kim CS, Law PY, Wei LN and Loh HH: A proteomics approach for identification of single strand DNA-binding proteins involved in transcriptional regulation of mouse mu opioid receptor gene. Mol Cell Proteomics 7: 1517-1529, 2008.

18. Cook RJ, Karch C, Nahar P, Rivera A and Ko JL: Effects of desferoxamine-induced hypoxia on neuronal human mu-opioid receptor gene expression. Biochem Biophys Res Commun 398: 56-61, 2010.

19. Schroth GP and Ho PS: Occurrence of potential cruciform and H-DNA forming sequences in genomic DNA. Nucleic Acids Res 23: 1977-1983, 1995.

20. Kang DH, Song KY, Wei LN, Law PY, Loh HH and Choi HS: Novel function of the poly(c)-binding protein $\alpha$-CP2 as a transcriptional activator that binds to single-stranded DNA sequences. Int J Mol Med 32: 1187-1194, 2013.

21. Patterson SD and Aebersold R: Mass spectrometric approaches for the identification of gel-separated proteins. Electrophoresis 16: 1791-1814, 1995.

22. Hwang CK, Wu X, Wang G, Kim CS and Loh HH: Mouse mu opioid receptor distal promoter transcriptional regulation by SOX proteins. J Biol Chem 278: 3742-3750, 2003.

23. Choi HS, Hwang CK, Kim CS, Song KY, Law PY, Wei LN and Loh HH: Transcriptional regulation of mouse mu opioid receptor gene: Sp3 isoforms (M1, M2) function as repressors in neuronal cells to regulate the mu opioid receptor gene. Mol Pharmacol 67: 1674-1683, 2005 .

24. Hardison RC: Comparative genomics. PLoS Biol 1: E58, 2003.

25. Wei LN and Loh HH: Transcriptional and epigenetic regulation of opioid receptor genes: Present and future. Annu Rev Pharmacol Toxicol 51: 75-97, 2011.

26. Vuillaumier S, Dixmeras I, Messaï H, Lapouméroulie C, Lallemand D, Gekas J, Chehab FF, Perret C, Elion J and Denamur E: Cross-species characterization of the promoter region of the cystic fibrosis transmembrane conductance regulator gene reveals multiple levels of regulation. Biochem J 327: 651-662, 1997. 